\title{
Molecular Analysis of Rabi Sorghum Genotypes Differing in Osmolytes Accumulation under Water Stress
}

\author{
S. V. Damame*, R. M. Naik, V. P. Chimote and S. V. Munjal
}

Dept. of Biochemistry, ${ }^{3}$ Biotechnology Centre Mahatma Phule Krishi Vidyapeeth, Rahuri, Maharashtra (413 722), India

\section{Article History}

Manuscript No. AR1544

Received in $6^{\text {th }}$ March, 2016

Received in revised form $28^{\text {th }}$ July, 2016

Accepted in final form $25^{\text {th }}$ September, 2016

\section{Correspondence to}

${ }^{*}$ E-mail: shivajidamame@gmail.com

\section{Keywords}

Sorghum, stay-green, osmolytes, RAPD, proline, glycinebetaine, genetic diversity

\begin{abstract}
Forty-eight sorghum accessions were screened for proline and glycine betaine osmolyte accumulation levels under-0.5 MPa PEG-6000 induced osmotic stress in the leaves of ten days old seedlings. Proline as well as glycine betaine accumulation was higher in stressed than unstressed condition. Under stressed conditions, tolerant sorghum genotypes exhibited highest increase in both the osmolytes, followed by stay-green and susceptible ones. Four each of drought susceptible, tolerant and stay-green sorghum genotypes differing in proline and glycine betaine accumulation potential under osmotic stress were analyzed with randomly amplified polymorphic DNA markers with a view to understand genetic diversity among the different types as well as proline and glycine betaine accumulation potential under water stress. Out of 43 primers screened, 26 amplified genomic DNA with 258 loci of which, 191 were polymorphic with $75.55 \%$ polymorphism. Among the random operon primers, thirteen showed twenty unique loci. The Dice similarity coefficient values based on RAPD data ranged from 0.70 to 0.91 with the minimum in a drought susceptible genotype RSV-1006 and the maximum in stay-green genotype M-35-1.The dendrogram revealed a separate major cluster of stay-green genotype, E-36-1.2D scatter plot showed a separate group of all four stay-green genotypes closely placed with two high proline accumulating tolerant genotypes, RSLG-262 and RSV-1366. However, two high glycine betaine accumulating tolerant genotypes, RSV-458 and Hadgaon local, appeared to be distinct from the stay-green genotypes.
\end{abstract}

\section{Introduction}

Sorghum [Sorghum bicolor (L.) Moench] forms the dietary staple of more than 500 millionpeople in more than 30 countries of the world (Dahlberg et al., 2011 ). The crop is the fifth most important cereal next only to rice, wheat, maize and barley in India. It is a self-pollinating, diploid $(2 n=2 x=20)$ with a genome size of $1 C=735 \mathrm{Mbp}$ which is about $25 \%$ the size of maize, or sugarcane. The sorghum is grown during both the seasons of kharif and rabi. In Maharashtra, it is mostly grown on the residual soil moisture, which generally suffers from severe moisture stress during the later stage of crop growth in rabi season. Drought is a major abiotic stress factor limiting crop production. Sorghum is well adapted to hot and dry environments and is regarded as a model crop for studying drought resistance among the grasses. The drought resistance is a complex trait and gene expression depends on the action and interaction of different morphological, physiological and biochemical characters
(Mitra, 2001; Dalal et al., 2012). Under stress condition, plant accumulates several kinds of compatible osmolytes such as proline, glycine betaine, sugar, alcohol and soluble protein (Delauney and Verma, 1993). The degree of stress tolerance has been positively correlated with the levels of organic solutes like proline and glycine betaine (GB) in a number of crop plants (Barnett and Naylor, 1996). Accumulation of proline under water deficit condition is considered to be an important character responsible for drought tolerance (Blum and Ebercon, 1976). It involves two major key regulatory enzymes such as pyrroline-5-carboxylate synthetase $\left(\mathrm{P}_{5} \mathrm{CS}\right)$ and proline oxidase. The former is involved in proline biosynthesis, and the latter in its degradation (Reddy et al., 2015). The GB is synthesized from phosphatidylcholine which accumulates in plants in a large quantity. Genetic transformations have allowed the introduction of new pathways for biosynthesis of various compatible solutes in plants, resulting in the production of transgenic plants with 
improved tolerance to stress. Transgenic plant accumulates GB at various levels and exhibit enhanced tolerance to several stresses (Sakamoto and Murata, 2002). The concentration of GB in such transgenic plant is generally low as compared to the levels observed in the stressed plant species that normally accumulate GB under stress. Two major factors have been identified that limit accumulation of glycine betaine in transgenic plants, the availability of endogenous choline itself (McNeil et al., 1999) and the transport of choline across the chloroplast envelope. Most sorghum plants show accelerated leaf senescence and premature death when drought occurs during grain-filling stage. Stay-green genotypes remain green due to a delay in leaf senescence and continue to fill grain under water-limited environments. Therefore, identification of genetic factors involved in plant responses to drought stress will provide the foundation to improve its drought resistance. Many studies have been carried outfor accessing patterns of sorghum genetic variation based on morphology (Appa-Rao et al., 1996; Shehzad et al., 2009), pedigree (Jorden et al., 1998) or phylogenetic diversity (Cheprot et al., 2013; Agrama et al., 2003). Various molecular and biochemical markers are available to differentiate variation in individuals. RAPD marker used in the present study because of it is one of the commonly used molecular technique based on PCR, their simplicity, speed and relatively low cost. However, the reproducibility of results is questioned, by using careful reaction components RAPD used extensively in various studies (Sharma et al., 2016). In the present study, both biochemical marker as well as molecular marker is used thoughtfully. Initially, drought susceptible and tolerant genotypes differing inproline and GB accumulation potential, under PEG-6000-induced osmotic stress i.e. high and low proline, and high and low GB containing genotypes were identified and further analyzed for RAPD polymorphism and compared with stay-green genotypes with view to find out relationship observed in biochemical parameters reflects in RAPD marker.

\section{Materials and Methods}

\subsection{Plant material}

The seeds of twenty-two drought tolerant and susceptible along withfour stay-green sorghum genotypes were collected from different locations of Maharashtra, however of same agro-ecological zone of Deccan plateau, hot semi-arid ecoregion. The sterilized petri-dishes of uniform size and shape were used to grow the sorghum seedlings. A fixed volume of sterilized liquid agar solution $(0.8 \%)$ was pouredinto petridishes and allowed to cool for solidification. The clean and viablesorghum seeds were surface-sterilized with $0.1 \%(\mathrm{w} / \mathrm{v})$ $\mathrm{HgCl}_{2}$ and washed 4-5 times with distilled water. The seeds were puton the agar medium. The petri dishes were kept in an incubator already maintained at $27 \pm 1{ }^{\circ} \mathrm{C}$ for seven days to obtain better initial germination and growth.The seedlings were then treated with an optimized osmotic stress of -0.5 MPa PEG-6000 solution, kept for three more days and unstressed without PEG served as control. The leaves of the ten days old seedling, given water stress with -0.5 MPa PEG6000 and the control (only $0.8 \%$ agar) were cut with a pair of scissors, weighed and used for proline and GB content.

\subsection{Plant analysis}

The leaves of the forty-eight genotypes were separately weighed and analyzed for proline (Bates et al., 1973) and glycine betaine (Stumpf, 1984). Based on proline and glycine betaine accumulation potential eight genotypes were selected, in which two each from high (RSLG-262 and RSV-1366) and low (SPV-504 and RSV-1006) proline accumulators and two each from high (RSV-458 and Hadgaon local) and low (RSV1045 and CSV-18) glycine betaine accumulators, in addition based on the data reported by the ICRISAT, India on \% green leaf area of several stay-green genotypes (Mahalakshmi and Bidinger, 2002), the most suitable four stay-green genotypes, B-35, E-36-1, M-35-1 and Sel-3 were selected in the present study for comparison (Table 1).

\subsection{DNA extraction and PCR assay}

Table 1: Characteristics of drought tolerant, susceptible and stay-green rabi sorghum genotypes

\begin{tabular}{|c|c|c|}
\hline $\begin{array}{l}\text { Sl. } \\
\text { No. }\end{array}$ & Genotypes & Pedigree \\
\hline A. & Tolerant genotypes & \\
\hline 1. & RSLG-262 (Maulee) & $\begin{array}{l}\text { Selection from local } \\
\text { germplasm }\end{array}$ \\
\hline 2. & RSV-1366 & SPV-1587×Phule Maulee \\
\hline 3. & RSV-458 (Anuradha) & RSLG-559×RSLG-1175 \\
\hline 4. & $\begin{array}{c}\text { Hadgaon local (H. } \\
\text { local) }\end{array}$ & $\begin{array}{l}\text { Selection from local } \\
\text { collection }\end{array}$ \\
\hline B. & Susceptible genotypes & \\
\hline 5. & SPV-504 (Swati) & SPV $86 \times M-35-1$ \\
\hline 6. & RSV-1006 (Revati) & CSV-216×SPV-1502 \\
\hline 7. & RSV-1045 & RSV-214×RSFR-9509 \\
\hline 8. & CSV-18 (SPV-1596) & CR-4×IS-18370 \\
\hline C. & Stay-green genotypes & \\
\hline 9. & B-35 & USA origin \\
\hline 10. & E-36-1 & Ethiopian origin \\
\hline 11. & M-35-1 & $\begin{array}{l}\text { Selection from local } \\
\text { Maldandi population }\end{array}$ \\
\hline 12. & Sel-3 & Selection from local Bedar \\
\hline
\end{tabular}


The isolation and purification of DNA from seedlings of various sorghum genotypes was performed as per the method described (Dellaporta and Wood, 1983) with some modifications. Concentration of purified DNA was measured using UV-visible spectrophotometer (Nanodrop, ND1000 USA) at 260 and $280 \mathrm{~nm}$ wavelengths. The ratio of absorbance at 260/280 was calculated which was $\sim 1.8$. Two $\mu l$ of all DNA extracts were electrophoresed (Bio Rad sub cell model 96 , USA) on $0.8 \%$ (w/v) agarose gel containing $0.5 \mu \mathrm{g} \mathrm{ml}^{-1}$ ethidium bromide at $6 \mathrm{Vcm}^{-1}$ in TBE buffer. After electrophoresis, the band intensity of genomic DNA was visualized on gel documentation unit (FluorChem TM Alpha Innotech, USA) and compared with standard DNA. These gels also provided a visual measure of purity and integrity of DNA. RAPD was performed using 43 random decamer primers obtained from Operon Biotechnologies, $\mathrm{GmbH}$, Germany. Amplification was performed in a $0.2 \mathrm{ml}$ PCR tubes as described (Arya et al., 2006) with some modifications. The $25 \mu \mathrm{l}$ reaction volume containing $1 \mathrm{U}$ Taq DNA polymerase, $2.5 \mu 110 \times$ PCR buffer and $0.2 \mu \mathrm{M}$ dNTPs mix. The PCR cycle consisted of initial denaturation at $94^{\circ} \mathrm{C}$ for $5 \mathrm{~min}, 40$ cycles of denaturation at $94{ }^{\circ} \mathrm{C}$ for one min, annealing at $37^{\circ} \mathrm{C}$ for one min and a final extension at $72{ }^{\circ} \mathrm{C}$ for $10 \mathrm{~min}$.

\subsection{Data analysis}

The data on biochemical characters were analyzed using completely randomized block design, whereas the UPGMA based dendrogram of twelve sorghum genotypes were generated with NTSYSpc 2.02i programme.

\section{Results and Discussion}

\subsection{Proline and glycine betaine accumulation under osmotic} stress

The data presented in Table 2 showed the effect of -0.5 MPa PEG-6000 -induced osmotic stress on proline and GB accumulation levels in the leaves of 10 days old sorghum seedlings. Screening of forty-eight sorghum genotypes revealed that tolerant genotypes, RSLG-262 and RSV1366 were found to accumulate the highest proline of 0.962 and $1.263 \mu$ moles $\mathrm{g}^{-1}$ fr.wt. respectively, whereas the genotypes, SPV-504 and RSV-1006 were the lowest proline accumulating ones from susceptible group under osmotic

Table 2: Effect of PEG-6000-induced osmotic stress on proline and glycine betaine content

\begin{tabular}{|c|c|c|c|c|c|c|c|}
\hline \multirow[t]{2}{*}{ Sl. No. } & \multirow[t]{2}{*}{ Genotypes } & \multicolumn{3}{|c|}{ Proline ( $\mu$ moles $\mathrm{g}^{-1}$ fr.wt.) } & \multicolumn{3}{|c|}{ Glycine betaine ( $\mu$ moles $\mathrm{g}^{-1}$ fr.wt.) } \\
\hline & & Unstressed & Stressed & $\%$ increase & Unstressed & Stressed & $\%$ increase \\
\hline A. & Tolerant genotypes & & & & & & \\
\hline 1. & RSLG-262 & 0.154 & 0.956 & 521 & 6.30 & 18.48 & 193 \\
\hline 2. & RSV-1366 & 0.147 & 1.263 & 759 & 7.68 & 21.78 & 185 \\
\hline 3. & RSV-458 & 0.145 & 0.562 & 288 & 8.40 & 33.48 & 299 \\
\hline \multirow[t]{2}{*}{4.} & Hadgaon local & 0.177 & 0.324 & 83 & 9.48 & 37.14 & 291 \\
\hline & Mean & 0.156 & 0.776 & 413 & 7.96 & 27.72 & 242 \\
\hline B. & Susceptible genotypes & & & & & & \\
\hline 5. & SPV-504 & 0.140 & 0.181 & 29 & 7.62 & 16.80 & 120 \\
\hline 6. & RSV-1006 & 0.142 & 0.233 & 64 & 6.60 & 14.40 & 118 \\
\hline 7. & RSV-1045 & 0.161 & 0.291 & 81 & 5.34 & 11.28 & 111 \\
\hline \multirow[t]{2}{*}{8.} & CSV-18 & 0.164 & 0.288 & 76 & 5.20 & 10.56 & 103 \\
\hline & Mean & 0.152 & 0.248 & 62.5 & 6.19 & 13.26 & 113 \\
\hline $\mathrm{C}$. & Stay-green genotypes & & & & & & \\
\hline 9. & B-35 & 0.159 & 0.309 & 94 & 12.30 & 28.74 & 133 \\
\hline 10. & E-36-1 & 0.179 & 0.350 & 96 & 12.24 & 28.08 & 130 \\
\hline 11. & M-35-1 & 0.164 & 0.339 & 107 & 11.52 & 27.78 & 141 \\
\hline \multirow[t]{3}{*}{12.} & Sel-3 & 0.147 & 0.293 & 99 & 11.04 & 22.98 & 108 \\
\hline & Mean & 0.162 & 0.323 & 99 & 11.78 & 26.90 & 108 \\
\hline & Comparison & S.E. \pm & $\mathrm{CD}(p=0.05)$ & & S.E. \pm & $\mathrm{CD}(p=0.05)$ & \\
\hline 1. & Genotypes & 0.041 & 0.113 & & 1.11 & 2.66 & \\
\hline 2. & Treatments & 0.008 & 0.023 & & 0.40 & 1.20 & \\
\hline 3. & Genotypes $\times$ Treatments & 0.058 & 0.16 & & 1.51 . & 3.85 & \\
\hline
\end{tabular}


stress condition. The tolerant genotypes, RSV-458 and Hadgaon local accumulated the highest glycine betaine of 33.48 and $37.14 \mu$ moles $\mathrm{g}^{-1}$ fr.wt. respectively, whereas the genotypes, RSV-1045 and CSV-18 were the lowest glycine betaine accumulating ones from the susceptible group under osmotic stress condition. The mean proline and glycine betaine contents were the higher in tolerant genotypes followed by stay-green and susceptible ones. Thus based on the proline and glycine betaine accumulation under standardized osmotic stressed condition, these twelve genotypes were used further for RAPD analysis.

Significantly, positive correlation was observed between the free proline content in leaves and PEG -induced osmotic stress in various crops. PEG -induced osmotic stress resulted in higher proline accumulation in sorghum (Jafar et al., 2004, Johnson et al., 2015). In severely stressed sorghum plants, proline accounted for more than $60 \%$ of the total free amino acids pooland it goes up to $80 \%$ in many plants (Wood et al., 1996; Matysik et al., 2002). Such accumulation of proline proposed to play an important role in the osmoadaptation or osmoprotectant in the plant cell (Savoure et al., 1995, Gill et al., 2014 ). Proline accumulation initiated in the leaves of all sorghum cultivars as the leaf water potential was reduced from -14 to -16 bars and higher correlation observed between relative water content and proline in wheat (Blum and Ebercon, 1976, Keyvan, 2010). Similar results were obtained in the present study, which may be due to multifunctional role of proline as a signaling molecule to modulate mitochondrial functions, influence cell proliferation or cell death and trigger specific gene expression, which can be essential for plant to recover from stress (Szabados and Savoure, 2009).

Another osmolytes GB alsoaccumulated at higher level in the drought tolerant and stay-green genotypes than the susceptible ones. The large number of sorghum germplasm of 240 lines showed the genetic differences in GB content (Yang et al., 2003). Glycine betaine level under water deficit condition, increased by 26 -fold in sorghum, while by doublein sugarcane (Wood et al., 1996, Abbas et al., 2014). Water deficit and salinity can lead to denaturation of proteins and disruption of membrane structures. Glycine betaine maintains the activity of enzymes under a variety of unfavorable conditions including high temperature, extremes of $\mathrm{pH}$ and high salt concentrations (Mickelbart et al., 1999). An increase in GB content on imposition of osmotic stress by PEG may be due to a role of GB in an adaptive response to abiotic environmental stress (Yang et al., 2003), by the enzyme choline monooxygenase activity, the rate-limiting step for GB synthesis and expression of gene induced under osmotic stress (Rathinasabapathi et al., 1997).

\subsection{RAPD evaluation of genomic DNAs in sorghum genotypes}

The genomic DNA were isolated from the selected four drought susceptible genotypes (viz., SPV-504, RSV 1006, RSV-1045, CSV-18), four drought tolerant genotypes (viz., RSLG-262, RSV-1366, RSV-458, Hadgaon local)which were also categorized into low and high proline and GB accumulating ones and fourstay-green genotypes (viz., B-35, E-36-1, M-35-1 and Sel-3). On RAPD analysis, out of 43 random decamer primers used only 26 primers amplified generating a total of 258 loci by amplification in the size range of 0.26 to $5.42 \mathrm{~kb}$., Out of them 191 loci were polymorphic with an average polymorphism of $75.55 \%$ (Table 3). Each primer thus produced on an average of 7.34 polymorphic loci. The $\%$ polymorphic bands with different primers ranged from 33.33 to $100 \%$, with OPA 04, OPC 20, OPD 04 and OPD 15 recording $100 \%$ polymorphism. The mean number of bands per accession ranged from 1.0 (with OPD 15 primer) to 12.25

\begin{tabular}{|c|c|c|c|c|c|c|c|c|}
\hline $\begin{array}{l}\text { Sl. } \\
\text { No. }\end{array}$ & $\begin{array}{c}\text { Random } \\
\text { primer }\end{array}$ & $\begin{array}{c}\text { Total } \\
\text { number of } \\
\text { bands }\end{array}$ & $\begin{array}{c}\text { No. of } \\
\text { band } \\
\text { position (locus) }\end{array}$ & $\begin{array}{l}\text { Mean no. } \\
\text { of bands } \\
\text { accession }^{-1}\end{array}$ & $\begin{array}{c}\text { Poly- } \\
\text { morphic loci } \\
\text { including unique loci* }\end{array}$ & $\begin{array}{l}\text { Mono- } \\
\text { morphic } \\
\text { loci }\end{array}$ & $\begin{array}{l}\text { \% Poly- } \\
\text { morphic } \\
\text { bands }\end{array}$ & $\begin{array}{l}\text { Fragment } \\
\text { size }(\mathrm{kb})\end{array}$ \\
\hline 1. & OPA 01 & 102 & 9 & 8.50 & 3 & 6 & 33.33 & 0.54 to 2.77 \\
\hline 2. & OPA 04 & 48 & 6 & 4.00 & 6 & 0 & 100.00 & 0.54 to 2.28 \\
\hline 3. & OPA 05 & 106 & 10 & 8.83 & $3(1)$ & 7 & 30.00 & 0.42 to 3.12 \\
\hline 4. & OPA 09 & 66 & 8 & 5.50 & 7 & 1 & 87.50 & 0.99 to 2.80 \\
\hline 5. & OPA 10 & 48 & 5 & 4.00 & 3 & 2 & 60.00 & 0.62 to 3.08 \\
\hline 6. & OPA 11 & 53 & 8 & 4.42 & $7(2)$ & 1 & 87.50 & 0.54 to 2.41 \\
\hline 7. & OPA 12 & 81 & 9 & 6.75 & $4(1)$ & 5 & 44.44 & 0.84 to 2.22 \\
\hline 8. & OPA 13 & 118 & 17 & 9.83 & 13 & 4 & 76.47 & 0.26 to 3.55 \\
\hline 9. & OPA 14 & 132 & 16 & 11.0 & $10(2)$ & 6 & 62.50 & 0.33 to 2.88 \\
\hline 10. & OPA 17 & 90 & 11 & 7.58 & 10 & 1 & 90.90 & 0.82 to 4.38 \\
\hline 11. & OPA 18 & 97 & 11 & 8.08 & $8(2)$ & 3 & 72.72 & 0.65 to 2.23 \\
\hline
\end{tabular}




\begin{tabular}{|c|c|c|c|c|c|c|c|c|}
\hline $\begin{array}{l}\text { Sl. } \\
\text { No. }\end{array}$ & $\begin{array}{c}\text { Random } \\
\text { primer }\end{array}$ & $\begin{array}{c}\text { Total } \\
\text { number of } \\
\text { bands }\end{array}$ & $\begin{array}{c}\text { No. of } \\
\text { band } \\
\text { position (locus) }\end{array}$ & $\begin{array}{l}\text { Mean no. } \\
\text { of bands } \\
\text { accession }^{-1}\end{array}$ & $\begin{array}{c}\text { Poly- } \\
\text { morphic loci } \\
\text { including unique loci }\end{array}$ & $\begin{array}{l}\text { Mono- } \\
\text { morphic } \\
\text { loci }\end{array}$ & $\begin{array}{l}\% \text { Poly- } \\
\text { morphic } \\
\text { bands }\end{array}$ & $\begin{array}{l}\text { Fragment } \\
\text { size }(\mathrm{kb})\end{array}$ \\
\hline 12. & OPA 19 & 54 & 11 & 4.50 & $10(3)$ & 1 & 90.90 & 0.27 to 2.91 \\
\hline 13. & OPC 05 & 118 & 17 & 9.83 & 13 & 4 & 76.47 & 0.33 to 2.93 \\
\hline 14. & OPC 09 & 38 & 8 & 3.17 & $7(3)$ & 1 & 87.50 & 0.76 to 2.73 \\
\hline 15. & OPC 11 & 67 & 8 & 5.58 & 7 & 1 & 87.50 & 0.91 to 2.30 \\
\hline 16. & OPC 19 & 35 & 8 & 2.92 & $7(1)$ & 1 & 87.50 & 0.73 to 2.62 \\
\hline 17. & OPC 20 & 68 & 12 & 5.67 & $12(1)$ & 0 & 100.00 & 0.33 to 2.43 \\
\hline 18. & OPD 04 & 50 & 6 & 4.17 & 6 & 0 & 100.00 & 0.63 to 2.53 \\
\hline 19. & OPD 08 & 109 & 13 & 9.08 & $8(1)$ & 5 & 61.54 & 0.55 to 3.67 \\
\hline 20. & OPD 11 & 127 & 13 & 10.58 & 6 & 7 & 46.15 & 0.37 to 2.77 \\
\hline 21 & OPD 15 & 12 & 2 & 1.00 & $2(1)$ & 0 & 100.00 & 1.87 to 2.45 \\
\hline 22. & OPD 18 & 147 & 15 & 12.25 & 11 & 4 & 73.33 & 0.27 to 3.19 \\
\hline 23. & OPE 06 & 109 & 13 & 9.08 & $12(1)$ & 1 & 92.30 & 0.55 to 3.62 \\
\hline 24. & OPE 08 & 57 & 7 & 4.75 & 5 & 2 & 71.42 & 0.78 to 2.83 \\
\hline 25 & OPE 12 & 49 & 6 & 4.08 & $4(1)$ & 2 & 66.66 & 1.77 to 5.42 \\
\hline 26. & OPE 14 & 64 & 9 & 5.33 & 7 & 2 & 77.77 & 0.82 to 3.64 \\
\hline
\end{tabular}

"Numbers given in parenthesis indicate unique loci.

(with OPD 18 primer). These primers amplified 20 unique loci in nine sorghum genotypes (except RSV-458, Hadgaon local and M-35-1) (Figure 1 and 2). The stay-green genotype E-36-1 recorded eight unique loci with the primers, OPA 5, OPA 11, OPA 12, OPA 19, OPC 9, OPD 8 and OPD 15. The

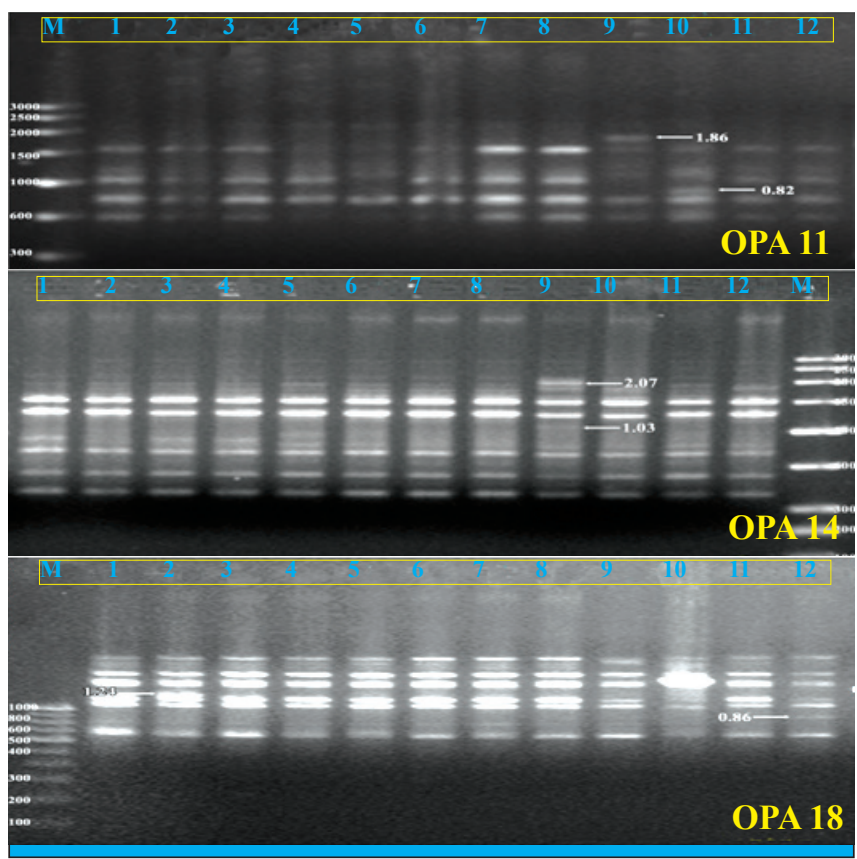

M: Marker, $\rightarrow$ : Arrow indicates unique band

Figure 1: RAPD amplification pattern of tolerant, susceptible and stay-green sorghum genotypes using primers, OPA11, OPA 14 and OPA 18.

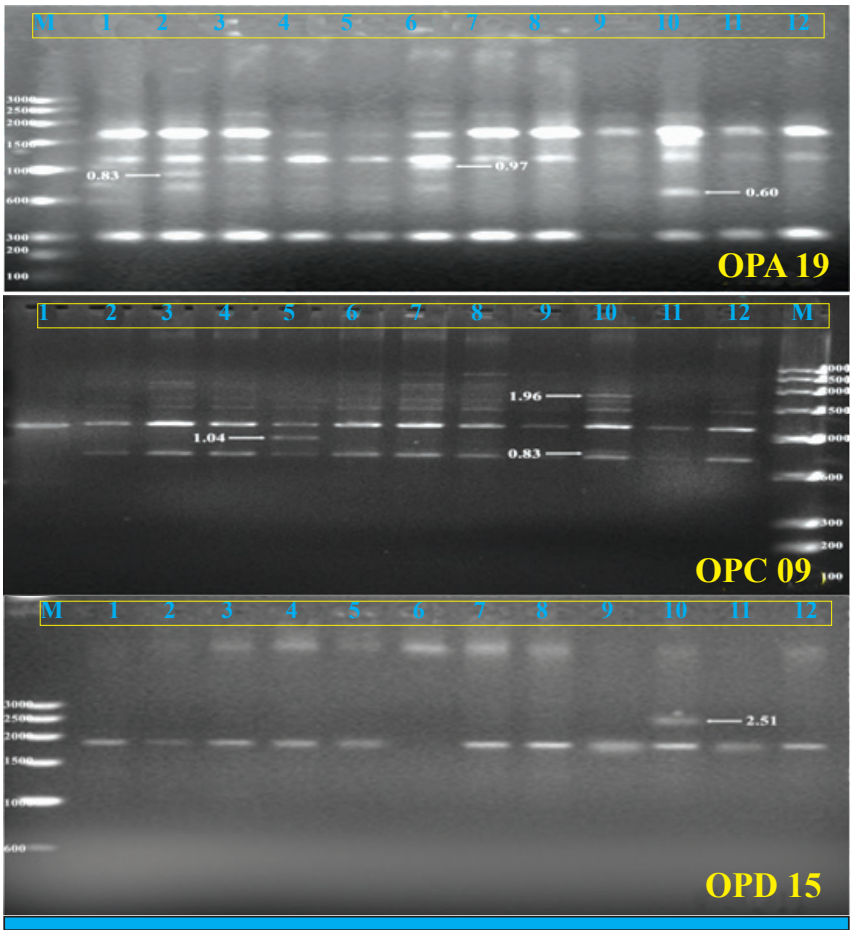

M: Marker, $\rightarrow$ : Arrow indicates unique band

Figure 2: RAPD amplification pattern of tolerant, susceptible and stay-green sorghum genotypes using primers, OPA 19, OPC 9 and OPD 15.

primers OPA 19 and OPC 9 produced three each unique loci in twelve sorghum genotypes. Among the markers generated by these random primers, a few putative genotype specific 
amplification products were generated which could be useful for germplasm classification and introgression studies.

\subsection{Genetic diversity analysis by RAPD markers}

Among the sorghum studied the pair wise similarity coefficient values genotypes ranged from 0.70 to 0.91 (Table 4), the maximum similarity noticed between drought susceptible genotypes, RSV-1006 and RSV-1045 and the minimum between drought susceptible genotype RSV-1006 and stay-green genotype M-35-1. However, the genetic diversity detected using molecular markers in the present investigation indicates moderate discrimination capacity of RAPD markers.

The UPGMA based dendrogram of 12 sorghum genotypes generated presented in Figure 3 revealed two major clusters. Second major cluster consisted of a single stay-green genotype E-36-1, whereas the first major cluster consisted of two sub-clusters. The second sub-cluster consisted of two stay-green genotypes, B-35 and M-35-1, however the first sub-cluster comprised of remaining four susceptible, four tolerant and one stay-green genotype. Further, in the first subcluster, one group comprised of one high proline genotype RSLG-262 and one stay-green genotype Sel-3. Another group consisted of both the high glycine betaine genotypes, RSV-458 and Hadgaon local. The genotype E-36-1 of the stay-green type was found to be the most divergent among the twelve dissimilar sorghum genotypes studied.

In the present investigation, genetic diversity was observed among 12 sorghum genotypes using RAPD markers that indicated its high discrimination capacity. From the similarity coefficient and consensus tree, it may be concluded that crossing between four drought tolerant, four drought susceptible and four stay-green genotypes with Dice similarity

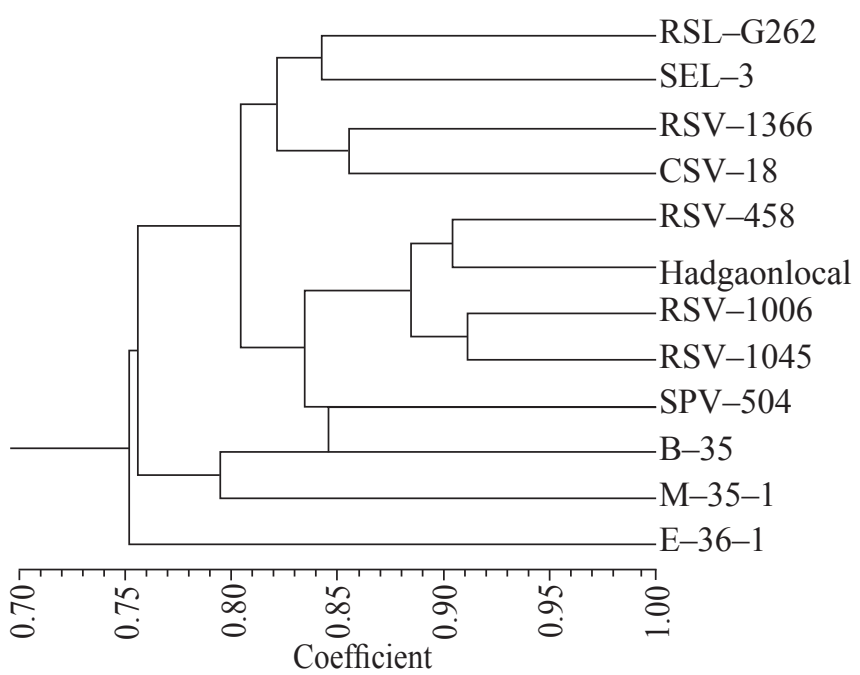

Figure 3: Consensus tree showing clustering of tolerant, susceptible and stay-green sorghum genotypes using RAPD analysis with NTSYSpc 2.02i software coefficient ranging from 0.70 to 0.91 fell in different clusters and sub clusters resulting in obtaining heterocyst in relation to drought tolerance. The maximum similarity coefficient of 0.91 was observed between two susceptible genotypes, RSV1006 and RSV-1045. The similarity coefficient of 0.90 was observed in two drought tolerant genotypes, RSV-458 and Hadgaon local, accumulating higher levels of GB osmolyte. The lowest similarity coefficient of 0.70 was observed in susceptible RSV-1006 and stay-green M-35-1 indicating their divergence.

Molecular analysis using 20 RAPD primers detected 121 loci, among which a total of 8 primers showed polymorphism, while 12 primers produced monomorphic pattern in sorghum genotypes.

Out of these amplified products, 33\% were polymorphic, each primer produced on an average of 6 loci with the size of amplified product ranging from 2.5 to $3.0 \mathrm{~kb}$ with $59.58 \%$ polymorphism (Tabasam et al., 2006). However, the higher polymorphism of $75.59 \%$ was observed in the present investigation. Twenty pearl millet genotypes were analyzed using 30 different 10-mer primers, however 12 primers revealed scorable polymorphism between genotypes of pearl millet, out of which 12 primers produced 99 polymorphic bands at an average of 8.25 polymorphic bands primer ${ }^{-1}$. Thus, the results obtained in the present investigation are in accordance with these reports (Govindaraj et al., 2009). In the present study, a total of 191 polymorphic bands with an average polymorphism of 7.34 bands were produced per primer. Genetic diversity among four wheat accessions analyzed by RAPD technique using 15 RAPD primers generated a total of 75 RAPD bands, 37 of these bands were found to be polymorphic. The number of amplification products per primer varied from 3 to 6 with a mean value of 5 . These primers produced fragments, which fell in the range of 250 to $2000 \mathrm{bp}$ in size. The calculated coefficient of similarity between all accessed genotypes varied between 0.627 and 0.76 (Iqbal and Bano, 2009). In the present study, analyses of genomic DNA of twelve sorghum genotypes using 26 RAPD primers depicted moderate diversity. The pair wise similarity coefficient values ranged from 0.70 in RSV-1006 and RSV1045 to 0.91 in M-35-1 and RSV-1006. The genotype E-361 appeared to be the most divergent and thus grouped in a separate cluster. Based on clustering pattern wide genetic diversity reported among the grain and forage type sorghum accessions (Sinha et al., 2014).

2D scatter plot showed a separate group of all four staygreen genotypes closely placed with two high proline accumulating tolerant genotypes, RSLG-262 and RSV-1366 (Figure 4) which may be due to high proline accumulated for the stabilization of proteins and protein complexes in 
the chloroplast and cytosol, protection of the photosynthetic apparatus and enzymes involved in ROS detoxification.

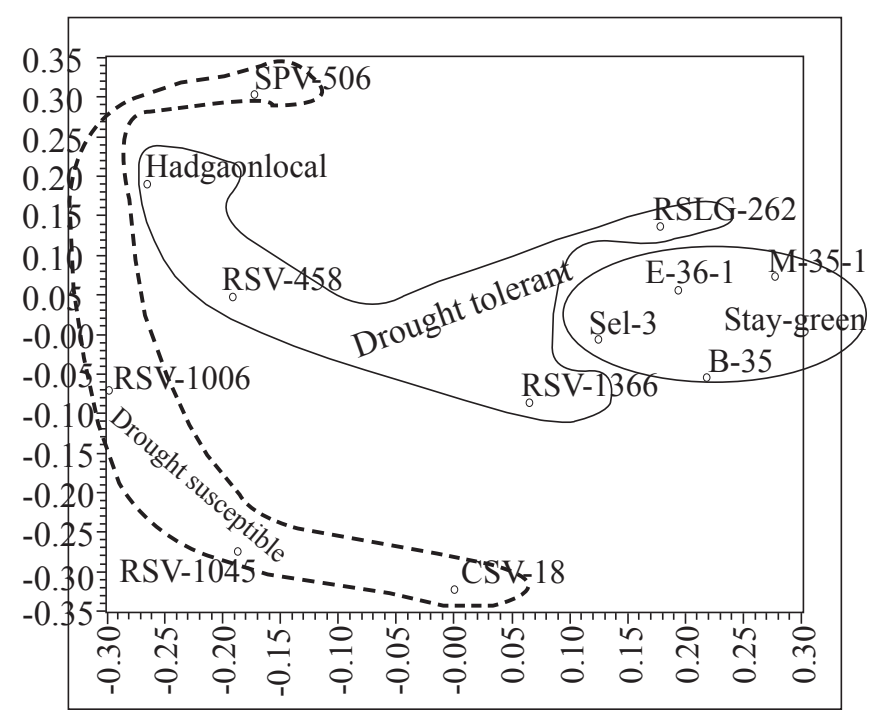

Figure 4: RAPD 2D PCO scatter plot of twelve sorghum genotypes

However, two high glycine betaine accumulating tolerant genotypes, RSV-458 and Hadgaon local appeared distinct from the stay-green genotypes, probably because of low level of induction of anti-oxidative enzymes.

\section{Conclusion}

The genotypes accumulating osmolytes under osmotic stress were divergent, however high proline accumulating and stay greengenotypes havemore similarity thus, could be further utilized in the breeding programme for enhancing drought tolerancecharacter in sorghum.

\section{References}

Abbas, S.R., Ahmad, S.D., Sabir, S.M., Shah, A.H., 2014. Detection of drought tolerant sugarcane genotypes (Saccharum officinarum) using lipid peroxidation, antioxidant activity, glycine-betaine and proline contents. Journal of Soil Science and Plant Nutrition 14 (1), 233-243.

Agrama, H.A., Tuinstra, M.R., 2003. Phylogenetic diversity and relationship among sorghum accessions using SSRs and RAPDs. African Journal of Biotechnology 2, 334340.

Appa-Rao, S., Prasada-Rao, K.E., Nandesha, M.H., GopalReddy, V., 1996. Morphological diversity in sorghum germplasm fron India. Genetic Resources and Crop Evolution 43, 559-567.

Arya, L., Sandhia, G.S., Singh, S. K., Rana, M.K., Malik, S.S., 2006. Analysis of Indian sorghum (Sorghum bicolor
(L) Monech) cultivars and lines using RAPD markers. Journal of Plant Biochemistry and Biotechnology 15, 97-101.

Barnett, N.M., Naylor, A.W., 1966. Amino acids and protein metabolism in Bermuda grass during water stress. Plant Physiology 41, 1222-1230.

Bates, L.S., Waldren, R.P., Teare, I.D., 1973. Rapid determination of free proline for water stress studies. Plant and Soil 39, 205-207.

Blum, A., Ebercon, A., 1976. Genotypic responses in sorghum to drought stress. III. Free proline accumulation and drought resistance. Crop Science 16, 428-431.

Cheprot, R.K., Matonyei, T.K., Were, B.A., Dangasuk, O.G., Onkware, A.O., Ouma, E.O., Too, E.J., Liu, J., Gudu, S., Kochian, L.V., 2013. Phylogenetic relationship among Kenyan sorghum germplasms based on aluminium tolerance. African Journal of Biotechnology, 2(22)3528-3536.

Dahlberg, J., Berenji, J., Sikora, V. and Latkovi, D., 2011. Assessing sorghum [Sorghum bicolor (L) Moench] germplasm for new traits: food, fuels \& unique uses. Maydica 56 (1750), 85-92.

Dalal, M., Mayandi, K., Chinnusamy, V., 2012. Sorghum: Improvement of abiotic stress tolerance. In:Improving Crop Resistance to Abiotic Stress, Volume $1 \&$ Volume 2, 923-950.

Delauney, A.J., Varma, D.P.S., 1993. Proline biosynthesis and osmoregulation in plants. Plant Journal 4, 215-223.

Dellaporta, S.L., Wood, J., 1983. AplantDNAminipreparation: Version II. Plant Molecular Biology Reporter 1, 19-21.

Gill, S.S., Gill, R., Anjum N.A., 2014. Target osmoprotectants for abiotic stress tolerance in crop plants-glycine betaine and proline. In: Anjum N.A., Gill, S.S., Gill, R., Plant adaptation to environmental change:Significance of amino acids and their derivatives. 97-108.

Govindaraj, M., Selvi, B., Arun Prabhu, D., Rajarathinam, S., 2009. Genetic diversity analysis of pearl millet (Pennisetum glaucum [L.] R. Br.,) accessions using molecular markers. African Journal of Biotechnology 8, 6046-6052.

Iqbal, S., Bano, A., 2009. Water stress induced changes in antioxidant enzymes, membrane stability and seed protein profile of different wheat accessions. African Journal of Biotechnology 8, 6576-6587.

Jafar, M.S., Nourmohamadi, G., Maleki, A., 2004. Effect of water deficit on seedlings, plantlets and compatible solutes of forage sorghum cv. Speedfeed. New directions for diverse planet. In Proceedings of $4^{\text {th }}$ International Crop Science Congress, Brisbane, Australia.Johnson, S.M., Cummins, I., Lim, F.L., 
Slabas, A.R. and Knight, M.R., 2015. Transcriptomic analysis comparing stay-green and senescent Sorghum bicolor lines identifies a role for proline biosynthesis in the stay-green trait. Journal of Experimental Botany, doi:10.1093/jxb/erv405, 1-13.

Jorden, D.R., Tao, Y.Z., Godwin, I.D., Henzel, R.G., Cooper, M., McIntyre, C.L., 1998. Loss of genetic diversity associated with selection from resistance to sorghum midge in Australia sorghum. Euphytica 102, 1-7.

Shamsi, K., 2010. The effects of drought stress on yield, relative water content, proline, soluble carbohydrates and chlorophyll of bread wheat cultivars. Journal of Animal \& Plant Sciences 8, 1051-1060.

Mahalakshmi, V., Bidinger, F.R., 2002. Evaluation of staygreen sorghum lines at ICRISAT. CropScience 42, 965-974. Matysik, J., Bhalu, B., Mohanty, P., 2002. Molecular mechanisms of quenching of reactive oxygen species by proline under stress in plants. Current Science 82, 525-532.

McNeil, S.D., Nuccio, M.L., Hanson, A.D., 1999. Betaines and related osmoprotectants, Targets for metabolic engineering of stress resistance. Plant Physiology 20, 945-949.

Mickelbart, M.V., Ejeta, G., Rhodes, D., Joly, R.J., Goldsbrough, P.B., 1999. Assessing the contribution of glycine betaine to environmental stress tolerance in sorghum, in Molecular approaches for the genetic improvement of cereals for stable production in water limited environment. In: a strategic planning workshop, held on 21-25 June, (CIMMYT 8 Batan Mexico USA, 86-89.

Mitra, J., 2001. Genetics and genetic improvement of drought resistance in crop plant. Current Science 80, 758-763.

Rathinasabapathi, B., Burnet, M., Russell, B.L., Gage, D.A., Liao, P.C., Nye, G.J., Scott, P., Golbeck, J.H., Hanson, A.D., 1997. Choline monooxygenase, an unusual ironsulfur enzyme catalyzing the first step of glycine betaine synthesis in plants. Prosthetic group characterization and cDNA cloning. In: Proceedings of National Academy of Science, United States of America 1997, 3454-58.

Reddy, P.S., Jogeswar, G., Rasineni, G.K., Maheswari, M., Reddy, A.R., Varshney, R.K., Kishor, P.K., 2015. Proline over-accumulation alleviates salt stress and protects photosynthetic and antioxidant enzyme activities in transgenic sorghum [Sorghum bicolor (L.) Moench]. Plant Physiology and Biochemistry 94, 104-113.

Sakamoto, A., Murata, N., 2002. The role of glycine betaine in the protection of plants from stress: Clues from transgenic plants. Plant Cell and Environment 25, 163171.

Savoure, A., Jaoua, S., Hua, X., Ardiles, W., Montagu, M.V., Verbruggen, N., 1995. Isolation, characterization and chromosomal location of a gene encoding $\Delta^{1}$-pyrroline5-carboxylate synthetase in Arabidopsis thaliana. FEBS Letter 372, 13-19.

Sharma, N., Kaur, R., Era, V., 2016. Potential of RAPD and ISSR markers for assessing genetic diversity among Stevia rebaudiana Bertoni accessions. Indian Journal of Biotechnology 15, 95-100.

Shehzad, T., Okuizumi, H., Kawase, M. and Okuno, K., 2009. Development of SSR-based sorghum (Sorghum bicolor (L.) Moench) diversity research set of germplasm and its evaluation by morphological traits. Genetic Resources \& Crop Evolution 56, 809.

Sinha, S., Kumaravadivel, N., Eapen, S., 2014. RAPD analysis in sorghum [Sorghum bicolor (L) Moench] accessions. International Journal of Bio-resources and stress management 5(3), 381-385.

Stumpf, D.K., 1984. Quantitation and purification of quaternary ammonium compounds from halophyte tissue. Plant Physiology 75, 273-274.

Szabados, L., Savoure, A., 2009. Proline: a multifunctional amino acid. Trends in Plant Science 15, 89-97.

Tabasam, N., Ur-Rahman, M., Jafar, Y., 2006. DNA-based genotyping of sorghum hybrids. Pakistan Journal of Botany 38, 1599-1604.

Wood, A.J., Saneoka, H., Rhodes, D., Joly, R.J., Goldsbrough, P.B., 1996. Betaine aldehyde dehydrogenase in sorghum (molecular cloning and expression of two related genes). Plant Physiology 110, 1301-1308.

Yang, W.Z., Patrick, J.R., Axtell, J.D., Wood, K.V., Bonham, C.C., Ejeta, G., Mickelbart, M.V., Rhodes, D., 2003. Genotypic variation in glycine betaine in sorghum. Crop Science 43, 162-169. 